Article (refereed) - postprint

Morandini, Virginia; Muriel, Roberto; Newton, lan; Ferrer, Miguel. 2019.

Skewed sex ratios in a newly established osprey population.

(C) Deutsche Ornithologen-Gesellschaft e.V. 2019

This version available http://nora.nerc.ac.uk/524535/

NERC has developed NORA to enable users to access research outputs wholly or partially funded by NERC. Copyright and other rights for material on this site are retained by the rights owners. Users should read the terms and conditions of use of this material at

http://nora.nerc.ac.uk/policies.html\#access

This is a post-peer-review, pre-copyedit version of an article published in Journal of Ornithology, 160 (4). 1025-1033. The final authenticated version is available online at:

https://doi.org/10.1007/s10336-019-01680-9

There may be differences between this version and the publisher's version. You are advised to consult the publisher's version if you wish to cite from this article.

\author{
Contact CEH NORA team at \\ noraceh@ceh.ac.uk
}

The NERC and CEH trademarks and logos ('the Trademarks') are registered trademarks of NERC in the UK and other countries, and may not be used without the prior written consent of the Trademark owner. 


\section{Skewed sex ratios in a newly established osprey} population

6

7

8

Virginia Morandini ${ }^{1}$, Roberto Muriel ${ }^{2}$, Ian Newton ${ }^{3}$, Miguel Ferrer $^{2 *}$

10 


\section{Abstract}

With recent increases in the numbers of reintroduction projects, it has become crucial to know the main factors that allow colonization of new areas and prevent the extinction of small and reintroduced populations. Dispersal is one of the most important phenomena in population biology with consequences to the proportion of individuals that keep breeding in the natal population and the number of individuals that move to other populations to breed. We studied changes in offspring sex ratio and differences in dispersal patterns between the sexes in a reintroduced population of Osprey (Pandion haliaetus). Results showed that at the beginning of the colonization process breeding pairs produced more males, which dispersed shorter distances and were more philopatric than females. However, with increasing breeding population size over the years, the offspring production was skewed to females, which dispersed longer distances from their natal area and tended to breed in different areas. Here we suggest that changes in offspring sex ratio during colonization processes, together with differences in dispersal pattern between sexes could influence colonization rate and the probability of success of future reintroduction projects.

Keywords: sex-ratio; osprey; colonization; dispersal; small populations 


\section{Introduction}

Offspring sex-ratio variation, and its possible consequences to populations, is a debated concept in population demography (Mayr 1939; Trivers and Willard 1973; Blank and Nolan 1983; Gowaty 1993; Becker et al.2008; Benito et al. 2013; Ferrer et al. 2013; Katzner et al. 2014). According to Fisher (1930) whenever the sex ratio of a population deviates from equilibrium, any genetic disposition to produce the rare sex will be favored by selection and the ratio will eventually return to equilibrium. In consequence, by natural selection sex ratios tend strongly to stick to the 1:1 ratio. Subsequent studies have identified numerous factors that can bias the sex ratio from 1:1, including local mate competition (Hamilton 1967), maternal condition (Trivers and Willard 1973), parent-offspring conflicts (Trivers 1974; Trivers and Hare 1976), and other unusual life history strategies or sex determination systems (Hardy 2002). Shyu and Caswell (2016) summarized which factors may modify the primary sex ratio, including differential offspring costs by sexes, mortality of offspring or parent mortality.

In sexually dimorphic species of raptors, differences in dispersal distances between sexes are often associated with differences in body size, (Newton 2008), affecting the capacity to connect with other populations (Muriel et al. 2016). In consequence, the dispersal patterns shown by populations of dimorphic species could be influenced by prevailing offspring sex ratios (Dale 2001).

Dispersal is one of the most important phenomena in population biology (Gadgil 1971), and may affect many aspects of demography in birds, influencing population dynamics and potential range of expansion (Newton 1998). Phylopatric behavior could benefit an animal in several ways, including pre-existing knowledge of the local environment and awareness that the area concerned can support a breeding population, however, it can also increases the risk of inbreeding (Ferrer et al. 2015).

In sexually dimorphic species, determining trends in sex ratios of patchy distributed populations becomes important in understanding population trends. Some studies show how differences in nestling sex ratios are correlated to population density (Santoro et al. 2015; Ferrer et al. 2009) or the availability of resources (Johnson et al. 2001; Arroyo 2002). Other studies have explored the effects of short or long term deviations in sex ratio for population dynamics (Gerlach and Le Maitre 2001; Ferrer et 
al. 2009; Ferrer et al. 2013; Lambertucci et al. 2013). Dispersal and metapopulation connectivity are key components of population dynamics. Connectivity affect significantly the risk of extinction, particularly in small populations (Newton 1998; Penteriani and Delgado 2009; Whitfield et al. 2009; Muriel et al. 2015). Reintroduced populations, with all individuals monitored since the beginning of the colonization, provide rare opportunities to examine the dispersal patterns in a colonization process and to analyze differences among individuals, population size and ages of breeders during different stages of the colonization process. If offspring sex ratio is biased in some stages of the colonization process, and the dispersal distances vary between sexes, that could have consequences in the metapopulation structure, and subsequently in the colonization success of the reintroduced population. According to that, some authors demonstrate that reintroduction programs may be less effective if the sex ratios of the released individuals are not considered (Dzialak et al. 2006; Bosé et al. 2007; Lenz et al. 2007; Lambertucci et al. 2013).

In the present study, we analysed trends in offspring sex ratios and natal dispersal patterns in both sexes in a reintroduced population of Ospreys (Pandion haliaetus) in southern Spain. For this marked population, information is available for all released individuals and surviving chicks hatched within the project since its inception.

\section{Methods}

\section{Study species}

The Osprey breeds on all continents except Antarctica, being resident in some areas and migratory in others (Poole 1989). It is a specialist fish-eating raptor; with a breeding dispersion ranging from solitary to loosely colonial (Poole 1989). Over the years, it has suffered heavily from various human impacts, becoming extinct over large areas due to human persecution in the late $19^{\text {th }}$ and early $20^{\text {th }}$ centuries (Poole 1989; Saurola 1997). In mainland Spain, after a continuing decline in the number of breeding pairs at least from the 1960s, the last breeding attempt took place in the province of Alicante in 1981 (Urios et al. 1991).

To re-establish the species, a reintroduction program was undertaken in Andalusia province, during the years 2003-12. Over this period, 180 young Ospreys were 
released by means of hacking (Dzialak et al. 2006) at two locations $125 \mathrm{~km}$ apart, a reservoir in the province of Cádiz and a coastal marshland in the province of Huelva (Fig. 1). The first breeding pair became established in 2005 in the province of Cádiz (Muriel et al. 2006) and the first successful pair reared a brood in 2009 in the same territory (Muriel et al. 2010).

The Iberian Peninsula is an important passage area for migratory Ospreys travelling between Europe and wintering areas in Africa, and a small number of northern European birds winter in southern Spain (Saurola 1997; Schmidt-Rothmund et al. 2014). Because of this, reintroduced populations in southern Spain are in regular contact with migratory individuals from other populations, being a partial migratory population with some of the breeding birds staying all year

\section{Data collection}

All released individuals were ringed with metal and PVC colour rings. They were obtained as chicks from populations further north in Europe, including Scotland (27), Germany (144) and Finland (20). We surveyed the study area at the beginning of each breeding season (January-February, during the courtship and nest site selection period; Poole 1989) to find any pairs that had settled and established territories. Nests were visited to ring the young when they reached 40 days old, providing information about the secondary sex ratio. In addition, the identity of every breeder was determined from the ring number. Non-ringed breeders were captured at the beginning of the breeding cycle using a dho-gaza mist net and an owl to attract the individual to the net; all individuals captured were ringed to allow individual identification thereafter. Some unringed individuals were identified over the years by their unique pattern of spots on the head feathers (Bretagnolle et al. 1994).

For our sex ratio analysis, we considered population size (as the total number of breeding pairs that year in each of the two release areas), age of breeders and sex ratio of all broods from 2009 (the year of first successful breeding) to 2016. The secondary sex ratio among young was expressed as the number of males per total number of nestlings in all broods at ringing, including only those broods composed of nontranslocated (locally produced) nestlings. In all, sex was determined for 86 wild-hatched 
nestlings in 39 different broods, using molecular analysis of feather samples (Ellegren 1996).

As the usual age of first breeding is considered as 3-4 years in Europe and the Mediterranean region (Dennis 2015), we considered as "young" any pair with at least one member younger than 5 years old.

In order to study the dispersal pattern of the population we analyzed data from 23-ringed breeding adults and assessed their natal dispersal distance (NDD; the distance between the breeding site and the natal nest). All territorial adults since 2005 were used in this analysis, including those released by hacking, considering the release site (hacking tower) as the natal location.

\section{Statistical analysis}

We conducted two analyses, one examining factors affecting variation in nestling sex ratio in the population since the first breeding pair in 2009, and another one examining factors affecting the dispersal distances among breeders.

Analyses were conducted using the STATISTICA 13.3 package (Statsoft Inc., Tulsa, USA) and R. First, we used a GLM analysis with sex ratio on the brood level as response variable and population size as continuous predictor to test correlation between them. Effect sizes and confidence intervals were also calculated. Then, in order to detect factors involved in sex ratio deviations, we used mixed models (GLMMs); with age of breeders (older or younger than 5 years) and released areas (Cadiz or Huelva) as fixed factors and population size as a covariate. The response variable (nestling sex) was binary, (1) male or (0) female. Therefore, we fitted GLMMs with a binomial error structure and logit link using the Imer function in R (Bates and Maechler 2010), adding brood identity as a random effect in the model (Krackow and Tkadlec 2001; Laaksonen et al. 2004; Katzner et al. 2014). In some cases, the age of the parent would not be determined, decreasing the sample size to 72 (instead of 86 used in analyses excluding age of the parents). Population size was expressed as number of pairs in each of the studied areas (Cadiz and Huelva) each year.

A generalized linear model GLM was used to check for differences in philopatry among the 23-ringed breeders. In this case, we used the logarithms of the dispersal distances to achieve normality. Logarithm of NDD was taken as the response variable, 
while sex and reintroduction (separating between reintroduced $n=19$, and wild individuals $n=4$ ) were included as fixed factors in the analysis.

\section{Results}

By 2016, the breeding population in southern Spain reached 23 pairs (13 pairs in Cadiz and 10 in Huelva). Throughout the study period (2009-2016), fledgling sex ratio was not found different from 1:1 (40 males, 46 females, $\chi 2=0.707, p=0.998)$. However, intrabrood offspring sex ratio was significantly affected by population size (GLM with sex ratio on the brood level as response variable and population size as continuous predictor; Wald statistic $=6.577, p=0.010$, Table 1 ), explaining $47 \%$ of the variance $\left(R^{2}=0.473\right)$. We found more production of males when population density was low and more production of females as density increases (24 males and 10 females in the period 2009-2012 vs. 16 males and 36 females in the period 2013-2016, Figure 2).

Offspring sex ratio was related to population size, but not to parental age. When the size of the breeding population increased, offspring sex ratio was increasingly biased toward females (Table 2). No differences between the Cádiz and Huelva populations were found (Table 2). From 2009, when the first two pairs bred successfully in southern Spain, until 2016, when the population reached 23 territorial pairs, the proportion of males declined from 0.8 to 0.26 (Figure 2). The total males and females produced over the study period were 40 and 46 respectively, but $78 \%$ of the total females and $40 \%$ of the total males were produced in the last 3 years (2014 to 2016).

The 23 ringed adults (10 females and 13 males) whose natal dispersal distances were known included 19 individuals released during the reintroduction project, 2 individuals coming from other populations (Morocco and Balearic Islands) and 2 hatched in the reintroduced populations. Interestingly, all the males (6 in Cadiz and 7 in Huelva) but only 3 females bred in their natal area ( 2 in Cadiz and 1 in Huelva), whereas 7 females but no males bred in a different area ( 4 females from Cadiz were found breeding in Huelva, 1 female from Huelva was found breeding in Cadiz, and 2 females each from Morocco and Balearic Islands were found breeding in Cadiz and Huelva, Fig 3). The differences between the sexes in natal dispersal distances were statistically significant 
217 (Table 3). Females showed higher natal dispersal distances than males, median values for NDD were $9.6 \mathrm{~km}$ in males and $183.6 \mathrm{~km}$ in females

\section{Discussion}

As previous studies suggest, the probability of a bird starting to breed in its own natal population depends largely on the chance of its finding a mate on an appropriate territory (Dale 2001; Lenz et al. 2007). For that reason, in breeding populations the optimal offspring sex-ratio is the one that balances the adult sex ratio, maximizing the number of breeding pairs and giving the highest population growth rate (Dale 2001; Lambertucci et al. 2013).

In a metapopulation context, the likelihood of individual dispersal between populations of different sizes and degrees of isolation is of central importance in understanding extinction and colonization dynamics. Our results showed a differential natal dispersal between males and females, as already shown in other studies of birds (Newton 1979, 2008; Greenwood and Harvey 1982) including Ospreys(Martell et al. 2002, Monti et al. 2014), with longer dispersal distances in females than in males. In Ospreys and other raptors, males are the smaller, more philopatric sex, while females are bigger and more liable to disperse further and breed in a different population. Under this scenario, the proportion of males in a new population is expected to limit local population growth, due to their reluctance to disperse large distances, reducing the probability to incorporate males coming from neighboring populations. We cannot discard that the higher NDD found in females is consequence of a sex-differential response to disturbance due to the reintroduction project. However previous studies showed that dispersal patterns of hacked birds are similar to those of non-hacked birds (Amar et al. 2000) and where differences were found in juvenile dispersal distances between reintroduced and hacked birds, differences were related to nutritional condition (Muriel et al. 2015), having similar effects in both sexes (Ferrer and Morandini 2017).

Even if the specific causes that create differences in biased offspring sex ratio during a colonization process are not being analyzed in our study, as Shyu and Caswell (2016) highlighted, there are sex-specific differences that can affect the offspring sex 
ratio, for example male and female offspring may differ in how they affect future parental reproduction. The philopatric sex that breeds closer to their parents tends to increase competition with its parents (Trivers 1985). According to that, a biased offspring sex ratio toward females will reduce the competition with her own parents in high-density populations. Nevertheless, our study populations seem to be still far from high density situation, consequently these potential benefits are not yet operating. Other factors might play a critical role in offspring sex ratio deviations, including seasonal effects, trade-off between resource availability, individual quality and the differential costs to produce the sex that enhances fitness the most (Wiebe et al. 1992; Dzus et al. 1996; Clout et al. 2002; Griffith et al. 2003; Szekély et al. 2004).

From an evolutionary viewpoint, producing more males at the beginning of the colonization process would have some benefits for the parents. At low densities, when high quality territories are available and competition for various resources is likely to be low, the philopatric sex would be favored (Ferrer and Donazar 1996; Kokko et al. 2004; Ferrer et al. 2008; Krüger et al. 2012). Later in the colonization process, when competition for territories is high, the dispersive sex should be favored, leaving them in a better position to find a nesting opportunity away from the natal area in another population with lower density.

In line with theory, we found changes in offspring sex ratios related to population size (Figure 2), with a tendency of breeders to produce more males at the beginning of the colonization process and more females when population size increased. It is important to point that in our study, we cannot separate the correlation between population size and "time", as the population tended to increase over the studied period, avoiding the possibility to compare a situation advanced in time but with a smaller population situation. similar trend, with more of the smaller, cheaper sex (males) produced when population density was low and more of the larger female offspring when density increased (Ferrer et al. 2009). In this case, variations in nestling sex ratio were associated with changes in the proportions of immature breeders, which tended to produce more males. As the proportion of breeders in immature plumage is density-dependent (Ferrer et al. 2003), it was not possible to discard an underlying effect of density on nestling sex ratio. Our 
Osprey population being in the early stages of establishment, tended to have a high proportion of young pairs and an absence of old birds. For this reason, findings concerning the relationship between sex ratio and parental age should be treated with caution. It is not possible in either study to eliminate the possibility that sex ratios changed through time for some very different reason, unrelated to either population density or age-composition of breeders. In addition, we only evaluated secondary, not primary sex ratio variation; therefore, we cannot determine mechanisms to achieve it (Bowers et al. 2013; Morandini and Ferrer 2015). Only further studies will help to separate these confounding factors, including the possibility of facultative brood reduction affecting secondary sex ratio.

Previous studies with Spanish imperial eagles, have also explored the relationship between nutritional conditions, presence of adults in the natal area and dispersal distances (Ferrer 1993b; Muriel et al. 2016; Morandini and Ferrer 2017). Individuals may be attracted by the presence of other breeders for settling (social attraction); in this sense, individuals released without adults in the area will tend to disperse longer distances than young with adults in their natal area do. In addition, under the "wandering hypothesis", individuals in better nutritional conditions will disperse longer distances than individuals in poor conditions, independently of availability of territories or the presence of adults in the area (Muriel et al. 2015; Muriel et al. 2016). If ospreys behave like imperial eagles, we would expect that reintroduced populations would show higher dispersal distances than established populations, regardless of changes in offspring sex ratios.

Breeding pairs occupying high quality territories in low density situations would be expected to provide better nutritional conditions to their offspring, with lower variance between occupied territories than in established populations in which both high and low quality territories are occupied (Ferrer and Donazar 1996; Ferrer et al. 2006; Ferrer et al. 2008). However, the wandering hypothesis applies only to juvenile dispersal distances in sedentary species. Nothing is known about its potential effect in migratory species and natal dispersal after migration. According to the social attraction hypothesis we expect longer dispersal distances in young Ospreys released without adults in the area (at the beginning of the reintroduction program), and no differences in the other two possibilities (i.e. released young with adults already breeding in the 
area and wild young). Further studies would be necessary to separate potential effects of social attraction and nutritional conditions, when the reintroduced population increases in density. Using the same population with different densities, we can avoid problems related to differences in spatial distribution and landscape features when comparing data from different populations (Morandini and Ferrer 2017). In reintroduction and reinforcement programs of species with sex-biased dispersal, the sex ratio of released individuals may influence the rate of population establishment. In spite of the difficulty of assigning a cause to changes in offspring sex ratios, consequences of a biased sex ratio seem to be associated with a differential dispersal behavior in a growing population. On this basis, when re-establishing a new population in a metapopulation context, our suggestion is to release mainly the most philopatric gender initially in order to attract conspecifics of the wandering sex. Depending on the possibilities of immigration from other populations, a large number of males during the first years of releases would be likely to increase the growth rate of the new Osprey population. However, different strategies could be carried out, depending on the distribution of other populations and the chances of immigration. We anticipate that our results could form a starting point for simulation models to predict the viability of connected small populations, taking account of sex differences in dispersal.

Acknowledgments We are grateful to Migres Foundation, CMAyOT (Consejería de Medio Ambiente y Ordenación del Territorio), Fundación Banco Santander and RECUPERA 2020 Project who funded this study.

\section{References}

Arroyo BE (2002) Fledgling sex ratio variation and future reproduction probability in

Amar A, Arroyo BE, Bretagnolle V (2000) Post-fledging dependence and dispersal in hacked and wild Montagu's Harriers Circus pygargus. Ibis, 142:21-28

Bates D, Maechler M (2010) Package "Ime4". Reference manual for the package, 
available at: http://cran.r-project.org/web/packages/Ime4/Ime4.pdf.

Becker PH, Ezard THG, Ludwigs JD, Sauer-Gürth H, Wink M (2008) Population sex ratio shift from fledging to recruitment: consequences for demography in a philopatric seabird. Oikos 117:60-68

Benito MM, Schielzeth H, González-Solís J, et al. (2013) Sex ratio adjustments in common terns: Influence of mate condition and maternal experience. J Avian Biol 44:179-188

Blank JL, Nolan V (1983) Offspring sex ratio in red-winged blackbirds is dependent on maternal age. Proc Natl Acad Sci USA 80:6141-6145

Bosé M, Le Gouar P, Arthur C, et al. (2007) Does sex matter in reintroduction of griffon vultures Gyps fulvus? Oryx 41:503-508

Bowers EK, Munclinger P, Bureš S, et al. (2013) Cross-fostering eggs reveals that female collared flycatchers adjust clutch sex ratios according to parental ability to invest in offspring. Mol Ecol 22:215-228

Bretagnolle V, Thibault JC, Dominici JM (1994) Field identification of individual ospreys using head marking pattern. J Wildl Manag 175-178

Clout MN, Elliott GP, Robertson BC (2002) Effects of supplementary feeding on the offspring sex ratio of kakapo: a dilemma for the conservation of a polygynous parrot. Biol Conserv 107:13-18

Dale S (2001) Female-biased dispersal, low female recruitment, unpaired males, and the extinction of small and isolated bird populations. Oikos 92:344-356

Dennis R (2015) Draft Recovery Action Plan for Ospreys inEurope and the Mediterranean Region in Particular.Convention on the Conservation of European Wildlife and Natural Habitats. Strasbourg, Council of Europe

Dzialak MR, Lacki MJ, Carter KM, et al. (2006) An assessment of raptor hacking during a reintroduction. Wildl Soc Bull 34:542-547

Dzus EH, Bortolotti GR, Gerrard JM (1996) Does sex-biased hatching order in bald eagles vary with food resources? Ecoscience 3:252-258

Ellegren $\mathrm{H}$ (1996) First gene on the avian W chromosome (CHD) provides a tag for universal sexing of non-ratite birds. Proc R Soc London B 263:1635-1641

Ferrer M (1993a) Juvenile dispersal behaviour and natal philopatry of a long-lived 
raptor, the Spanish Imperial Eagle Aquila adalberti.lbis 135:132-138.

Ferrer M (1993b) Ontogeny of dispersal distances in young Spanish imperial eagles.

Ferrer M, Donazar JA (1996) Density-dependent fecundiyt by habitat heterogeneity in an increasing population of spanish imperil eagles. Ecology 77:69-74

Ferrer M, Morandini V (2017) Better nutritional condition changes the distribution of juvenile dispersal distances: an experiment with Spanish imperial eagles. J Avian Biol 48: 1342-1347.

Ferrer M, Morandini V, Newton I (2015) Floater interference reflects territory quality in the Spanish Imperial Eagle Aquila adalberti : a test of a density-dependent mechanism. Ibis 157:849-859

Ferrer M, Newton I, Casado E (2006) How to test different density-dependent fecundity hypotheses in an increasing or stable population. J Anim Ecol 75:111117

Ferrer M, Newton I, Casado E (2008) Density dependence hypotheses and the distribution of fecundity. J Anim Ecol 77:341-345

Ferrer M, Newton I, Muriel R (2013) Rescue of a small declining population of Spanish imperial eagles. Biol Conserv 159:32-36

Ferrer M, Newton I, Pandolfi M (2009) Small populations and offspring sex-ratio deviations in eagles. Conserv Biol 23:1017-1025

Ferrer M, Penteriani V, Balbontín J, Pandolfi M (2003). The proportion of immature breeders as a reliable early warning signal of population decline: evidence from the Spanish imperial eagle in Doñana. Biol Conserv 114:463-466

Gadgil M (1971) Dispersal: population consequences and evolution. Ecology 52:253261

Gerlach J, Le Maitre S (2001). Sex ratio variation in small island populations of an endangered bird, the Seychelles magpie robin, Copsychus sechellarum. Ostrich 72:114-117

Griffith S, Örnborg J, Russell A, Andersson S, Sheldon B (2003) Correlations between ultraviolet coloration, overwinter survival and offspring sex ratio in the blue tit. J Evol Biol 16:1045-1054

Gowaty PA (1993) Differential dispersal , local resource competition, and sex ratio 
variation in birds. Am Nat 141:263-280

Greenwood PJ, Harvey PH (1982)The natal and breeding dispesal of birds. Annu Rev Ecol Syst 13:1-21

Hanski I (1998) Metapopulation dynamics. Nature 396:41-49

Johnson CN, Clinchy M, Taylor AC, Krebs CJ, Jarman PJ, Payne A, Ritchie EG (2001) Adjustment of offspring sex ratios in relation to the availability of resources for philopatric offspring in the common brushtail possum. Proc R Soc London B 268: 1480

Katzner TE, Jackson DS, Ivy J, Bragin EA, DeWoddy, A (2014). Variation in offspring sex ratio of a long-lived sexually dimorphic raptor, the Eastern Imperial Eagle Aquila heliaca. Ibis 156:395-403

Kokko H, Harris MP, Wanless S (2004) Competition for breeding sites and sitedependent population regulation in a highly colonial seabird, the common guillemot Uria aalge. J Anim Ecol 73:367-376

Krackow S, Tkadlec E (2001) Analysis of brood sex ratios: Implications of offspring clustering. Behav Ecol Sociobiol 50:293-301

Krüger O, Chakarov N, Nielsen JT, Looft V, Grünkorn T, Struwe-Juhl B, Møller AP (2012) Population regulation by habitat heterogeneity or individual adjustment? J Anim Ecol 81:330-340

Laaksonen T, Fargallo JA, Korpimäki E, Lyytinen S, Valkama J, Pöyri V (2004) Year-and sex-dependent effects of experimental brood sex ratio manipulation on fledging condition of Eurasian kestrels. J Anim Ecol 73:342-352

Lambertucci SA, Carrete M, Speziale KL, Hiraldo F, Donazar JA (2013). Population sex ratios: another consideration in the reintroduction - reinforcement debate? PLoS One 8:e75821

Lenz TL, Jacob A, Wedekind C (2007) Manipulating sex ratio to increase population growth: The example of the Lesser Kestrel. Anim Conserv 10:236-244

López-López P, Zuberogoitia I, Alcántara M, Gil JA(2013) Philopatry, natal dispersal, first settlement and age of first breeding of bearded vultures Gypaetus barbatus in central Pyrenees. Bird Study 60:555-560

Martell MS, Englund JV, Tordoff HB (2002) An urban Osprey population established by translocation. J Raptor Res 36:91-96 
Mayr E (1939) The Sex Ratio in Wild Birds. Am Nat 73:156-179

Monti F, Dominici JM, Choquet R,Duriez O, Sammuri G, Sforzi A (2014) The Osprey reintroduction in Central Italy: dispersal, survival and first breeding data. Bird Study 61:465-473

Morandini V, Ferrer M (2015) Sibling aggression and brood reduction: A review. Ethol Ecol Evol 27:2-16

Morandini V, Ferrer M (2017) Natal philopatry: local experience or social attraction? An experiment with Spanish imperial eagles. Anim Behav 130:153-157

Muriel R, Ferrer M, Casado E, Schmidt D(2006) First breeding success of Osprey (Pandion haliaetus ) in mainland Spain since 1981 using cross-fostering. J Raptor Res 40:303-304

Muriel R, Ferrer M, Casado E, Calabuig CP(2010) First successful breeding of reintroduced ospreys pandion haliaetus in mainland Spain. Ardeola 57:175-180

Muriel R, Morandini V, Ferrer M, Balbontin J (2015) Independence and juvenile dispersal distances in wild and reintroduced Spanish imperial eagles. Biol. Conserv., 191:300-305.

Muriel R, Morandini V, Ferrer M, Balbontin J (2016) Juvenile dispersal behaviour and conspecific attraction : an alternative approach with translocated Spanish imperial eagles. Anim Behav 116:17-29

Newton I (1979) Population ecology of raptors. London: T\&AD Poyser

Newton I (1998) Population limitation in birds. Academic press

Newton I (2008) The migration ecology of birds. Amsterdam, The Netherlands: Academic Press

Penteriani V, Delgado MM (2009) Thoughts on Natal Dispersal. J Raptor Res 43:90-98 Penteriani V, Ferrer M, Delgado MM (2011) Floater strategies and dynamics in birds, and their importance in conservation biology: Towards an understanding of nonbreeders in avian populations. Anim Conserv 14:233-241

Poole AF (1989) Ospreys: a natural and unnatural history. Cambridge University Press. Santoro S, Green AJ, Speakman JR, Figuerola J (2015) Facultative and non-facultative sex ratio adjustments in a dimorphic bird species. Oikos 124:1215-1224

Saurola P (1997) The Osprey (Pandion haliaetus) and modern forestry: a review of population trends and their causes in Europe. J Raptor Res 32:129-137 
471 Schmidt-Rothmund D, Dennis R, Saurola P (2014). The Osprey in the Western

472 Palearctic : breeding population size and trends in the early 21 st century. J Raptor $473 \quad$ Res 48:375-386

474 Shyu E, Caswell H (2016) A demographic model for sex ratio evolution and the effects 475 of sex-biased offspring costs. Ecol Evol 6:1470-1492

476 Szekély T, Cuthill IC, Yezerinac S, Griffiths R, Kis J (2004) Brood sex ratio in the Kentish 477 plover. Behav Ecol 15:58-62

478 Trivers RL, Willard DE (1973) Natural selection of parental ability to vary the sex-ratio of offspring. Science 179:90-92

Whitfield DP, Douse A, Evans RJ,Grant J, Love J, et al. (2009) Natal and breeding dispersal in a reintroduced population of White tailed Eagles Haliaeetus albicilla. Bird Study 56:177-186 
487 Table 1: Result of GLM analysis with sex ratio on the brood level as response variable 488 and population size as continuous predictor to test correlation between them.

$489 \quad$ Confidence intervals were also calculated.

490

491

\begin{tabular}{|l|c|c|c|c|c|c|}
\hline Effect & Estimate & $\begin{array}{c}\text { Standard } \\
\text { Error }\end{array}$ & Wald Stat. & $\begin{array}{c}\text { Lower } \mathrm{CL} \\
95.0 \%\end{array}$ & $\begin{array}{c}\text { Upper } \mathrm{CL} \\
95.0 \%\end{array}$ & $\mathrm{p}$ \\
\hline Intercept & -0.0575 & 0.2734 & 0.0444 & -0.5935 & 0.4782 & 0.8329 \\
\hline territorial pairs & -0.0523 & 0.0204 & 6.5776 & -0.0924 & -0.0123 & 0.0103 \\
\hline
\end{tabular}

492

493

494

495

496

497

498

499 
500 Table 2: Result of binomial GLMM considering the sex of an individual (probability of 501 being male) as the response variable ( $N=72)$. Age of parents ("young" and "old") and 502 population identity (Cádiz or Huelva) were analyzed as fixed factors. Annual population 503 size, expressed as number of pairs in each of the studied areas (Cadiz and Huelva) each 504 year, was included as covariate. Confidence intervals (95\%) are also presented 505 (estimates are in log scale in a binomial model), and $R^{2}$ marginal (fixed effects) and 506 conditional (fixed and random effects together).

507

\begin{tabular}{|l|l|l|l|l|}
\hline & Estimate & Std. Error & $\mathbf{z}$ value & P value \\
\hline Intercept & 5.969 & 2.958 & 2.018 & 0.0436 \\
\hline Age & -0.946 & 0.762 & -1.241 & 0.2147 \\
\hline Population identity & -1.233 & 0.863 & -1.429 & 0.1531 \\
\hline Population size & -0.316 & 0.129 & -2.436 & 0.0149 \\
\hline
\end{tabular}

508

509

Random effects:

\begin{tabular}{|l|l|l|}
\hline Groups Name & Variance & Std.Dev. \\
\hline Brood (Intercept) & 0.249 & 0.498 \\
\hline
\end{tabular}

510

511 Confidence interval (95\%)

\begin{tabular}{|l|l|l|l|}
\hline & Estimates & $2.5 \%$ & $97.5 \%$ \\
\hline Intercept & 5.969 & 0.669 & 13.385 \\
\hline Age & -0.946 & -2.734 & 0.552 \\
\hline Population identity & -1.232 & -3.323 & 0.396 \\
\hline Population size & -0.315 & -0.644 & -0.091 \\
\hline
\end{tabular}

$\mathrm{R}^{2}$ marginal (fixed effects) and conditional (fixed and random effects together)

515

\begin{tabular}{|l|l|l|l|}
\hline Family & Link & Marginal & Conditional \\
\hline Binomial & logit & 0.1891 & 0.2462 \\
\hline
\end{tabular}


518 Table3: Result of GLM (normal distribution and identity link function) considering natal 519 dispersal distance (log-transformed) as response variable. Factors included in the 520 analysis were sexes (male or female) and origin (wild or reintroduction).

521

522

\begin{tabular}{|l|c|c|c|c|c|}
\hline Effect & SS & df & MS & $F$ & $p$ \\
\hline Intercept & 1981.679 & 1 & 1981.697 & 1556.271 & $<0.001$ \\
\hline (1) Sex & 24.123 & 1 & 24.123 & 18.945 & $<0.001$ \\
\hline (2) Reintroduction & 1.172 & 1 & 1.172 & 0.921 & 0.352 \\
\hline
\end{tabular}

523 
525 Figure 1: Osprey population in Southern Spain. First nests appeared in Cádiz population and in 526 Huelva population are represented in black, the following nests are represented in gray. Division between populations area represented by the limit of the provinces (Cádiz and Huelva).

528

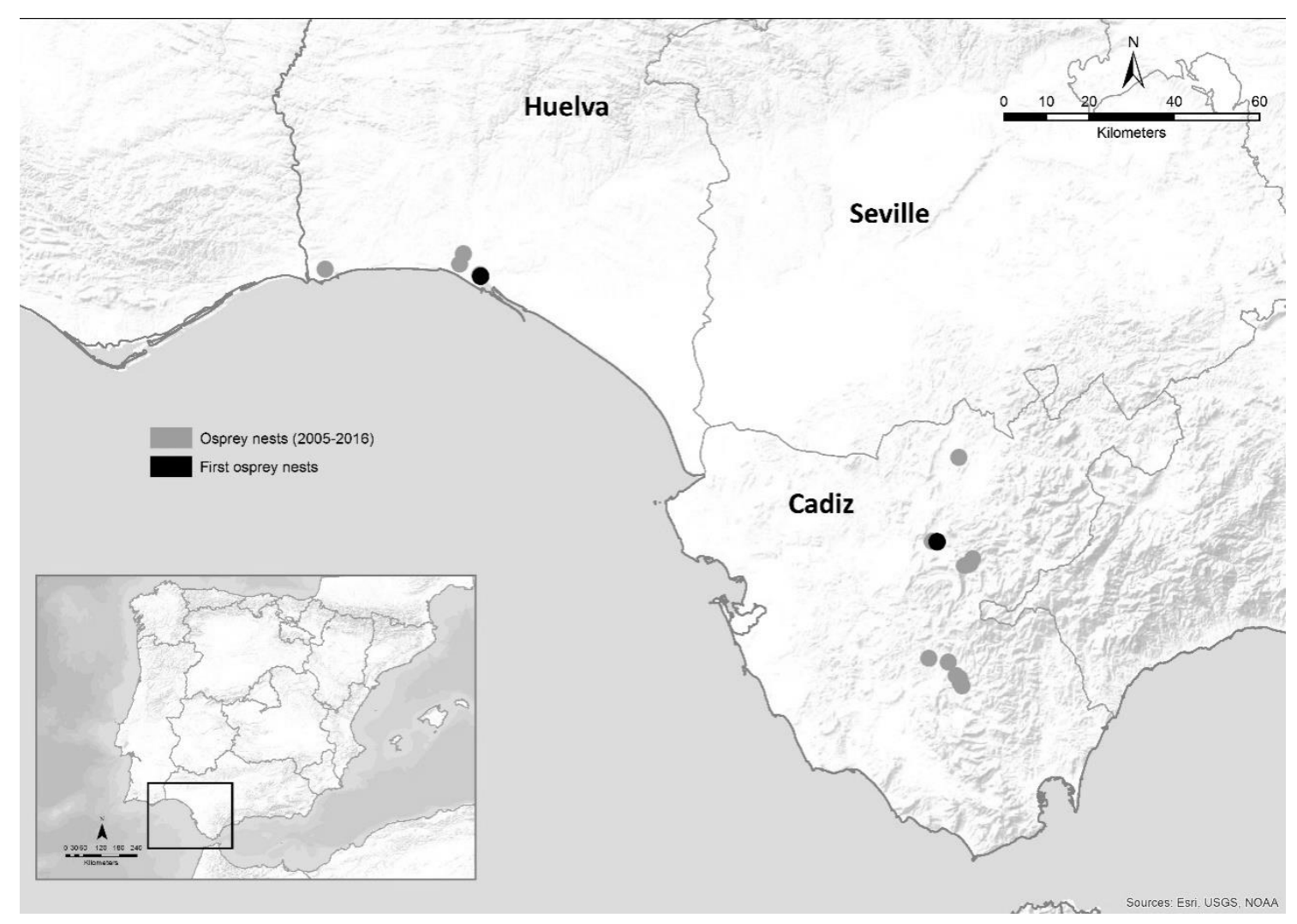

529

530

531

532

533

534

535

536

537

538

539

540

541

542

543 
544 Figure 2: Annual number of pairs and offspring sex ratio (expressed as number of males/total 545 number of nestlings per year) of the reintroduced Osprey populations in south of Spain from 5462009 to 2016 . The $95 \%$ Wilson confidence intervals are included for offspring sex ratios each 547 year.

548

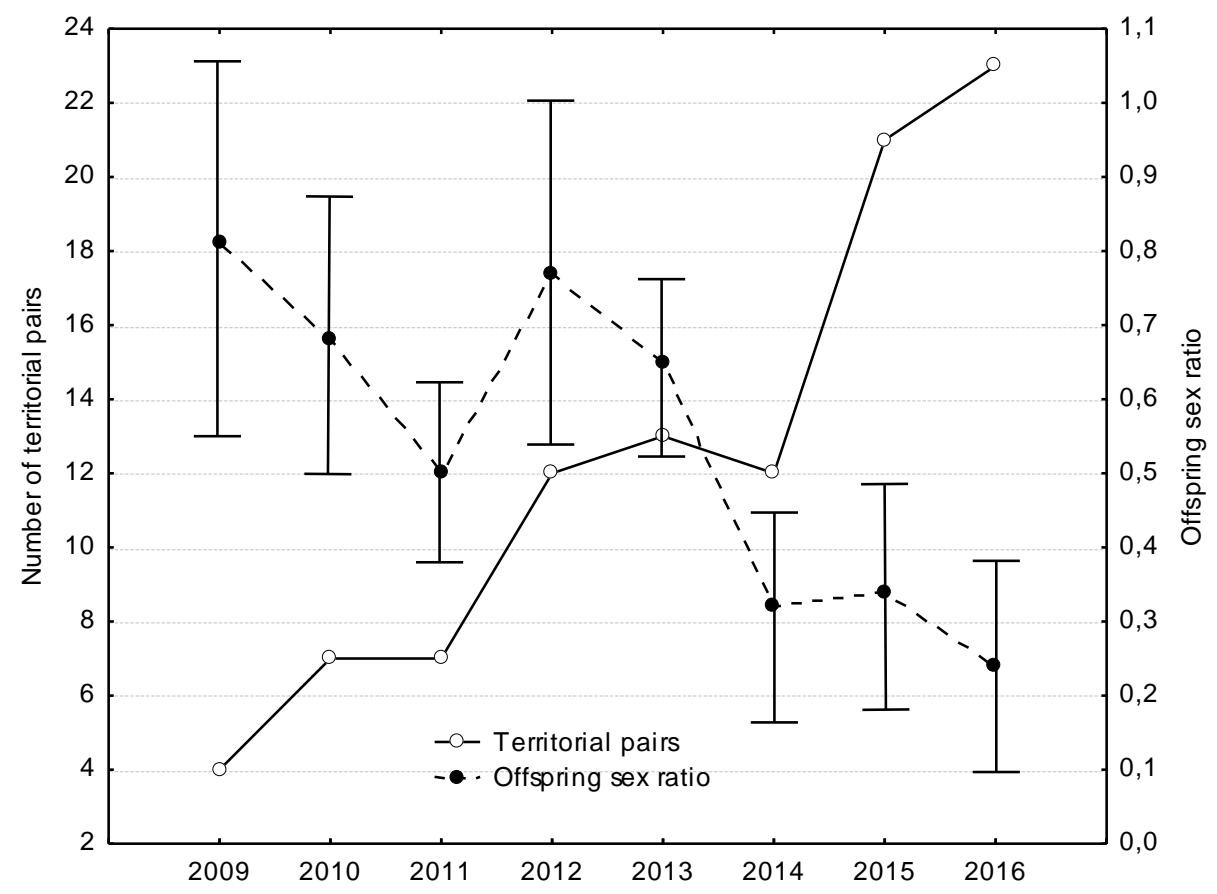


553

554

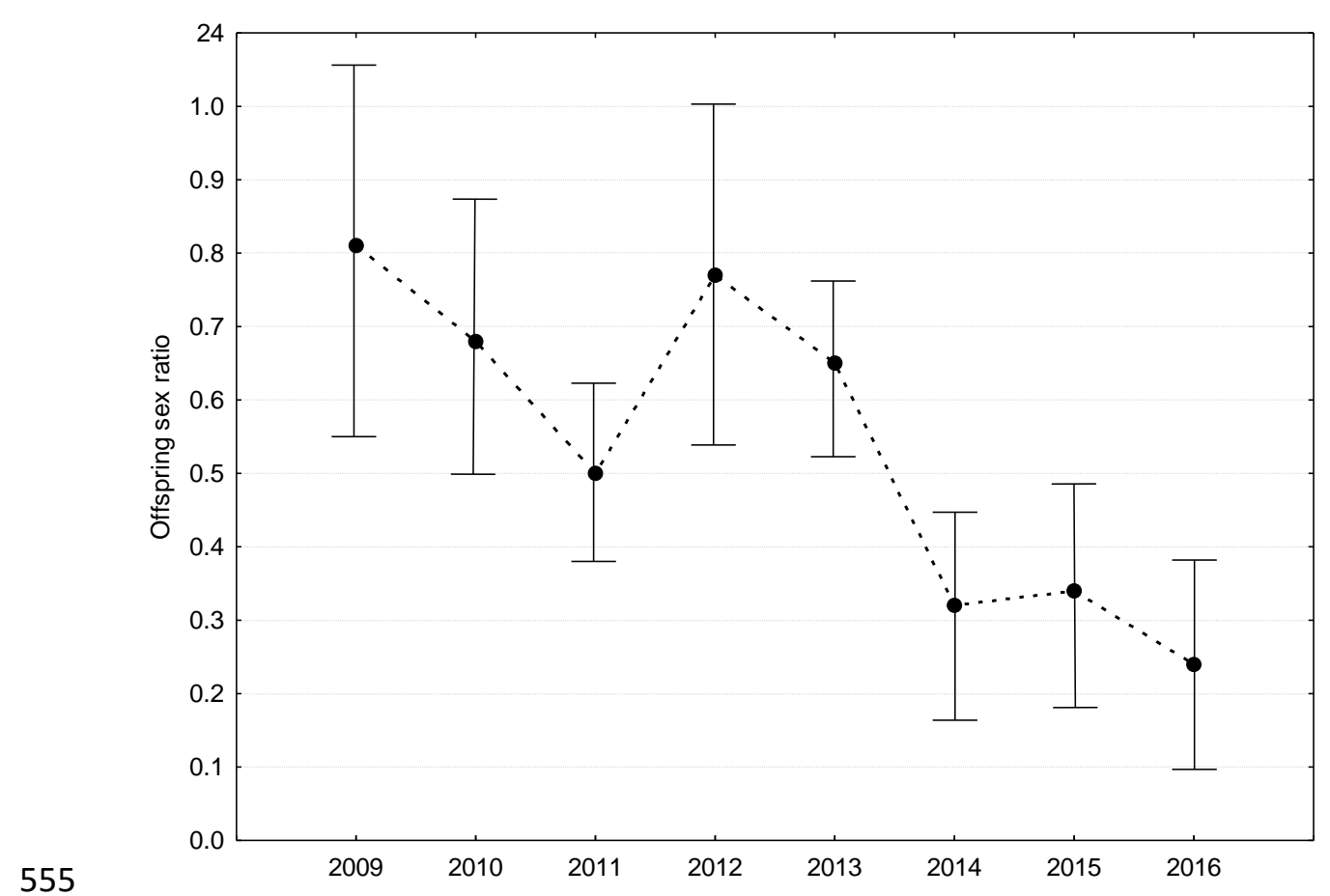

556

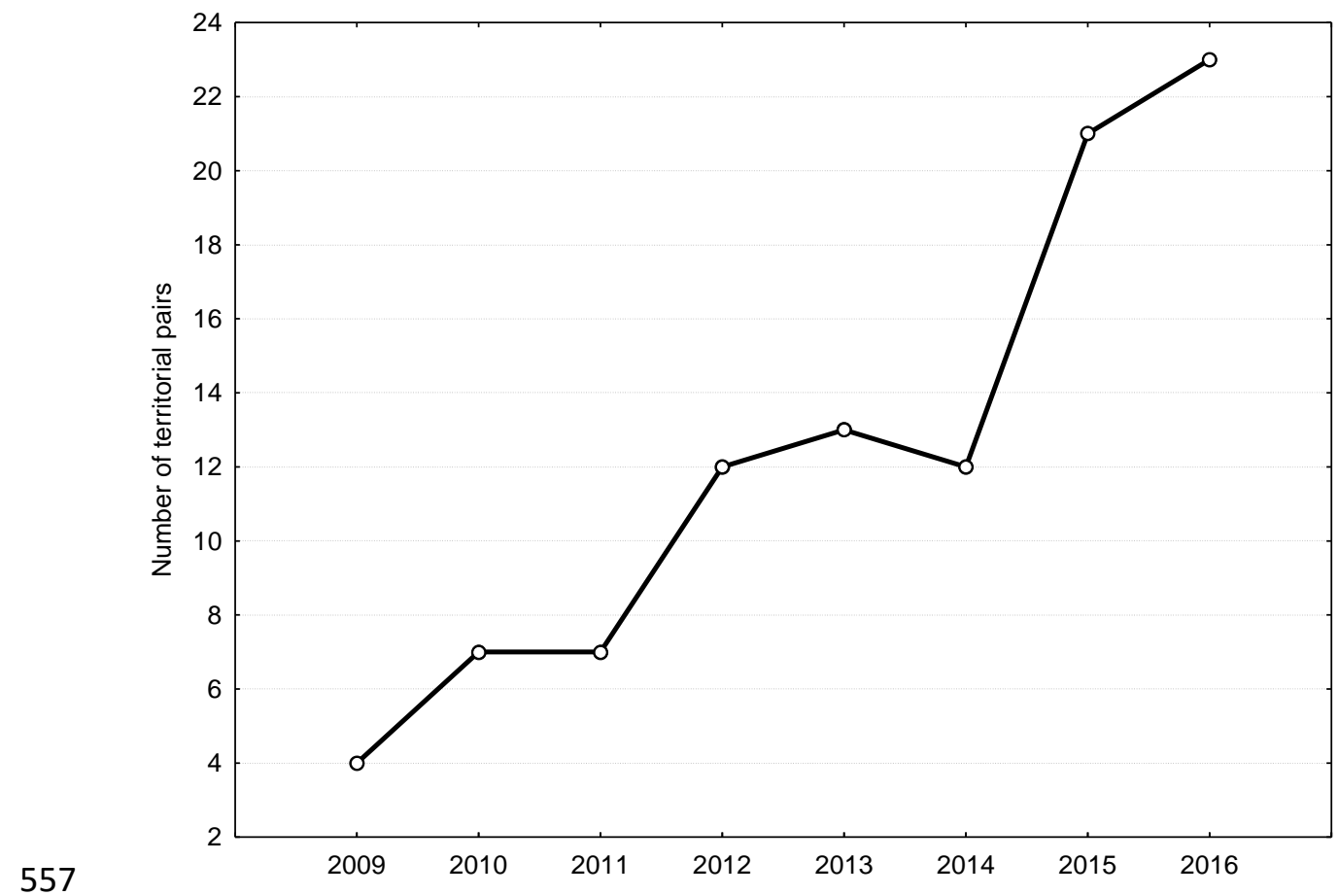

558

559

560 
561 Figure 3: Distribution of breeding dispersal distances of females and males considering the 562 location of the natal nest and the first breeding nest. For individuals released by hacking, the 563 release site (hacking tower) was considered as the natal location

564

565
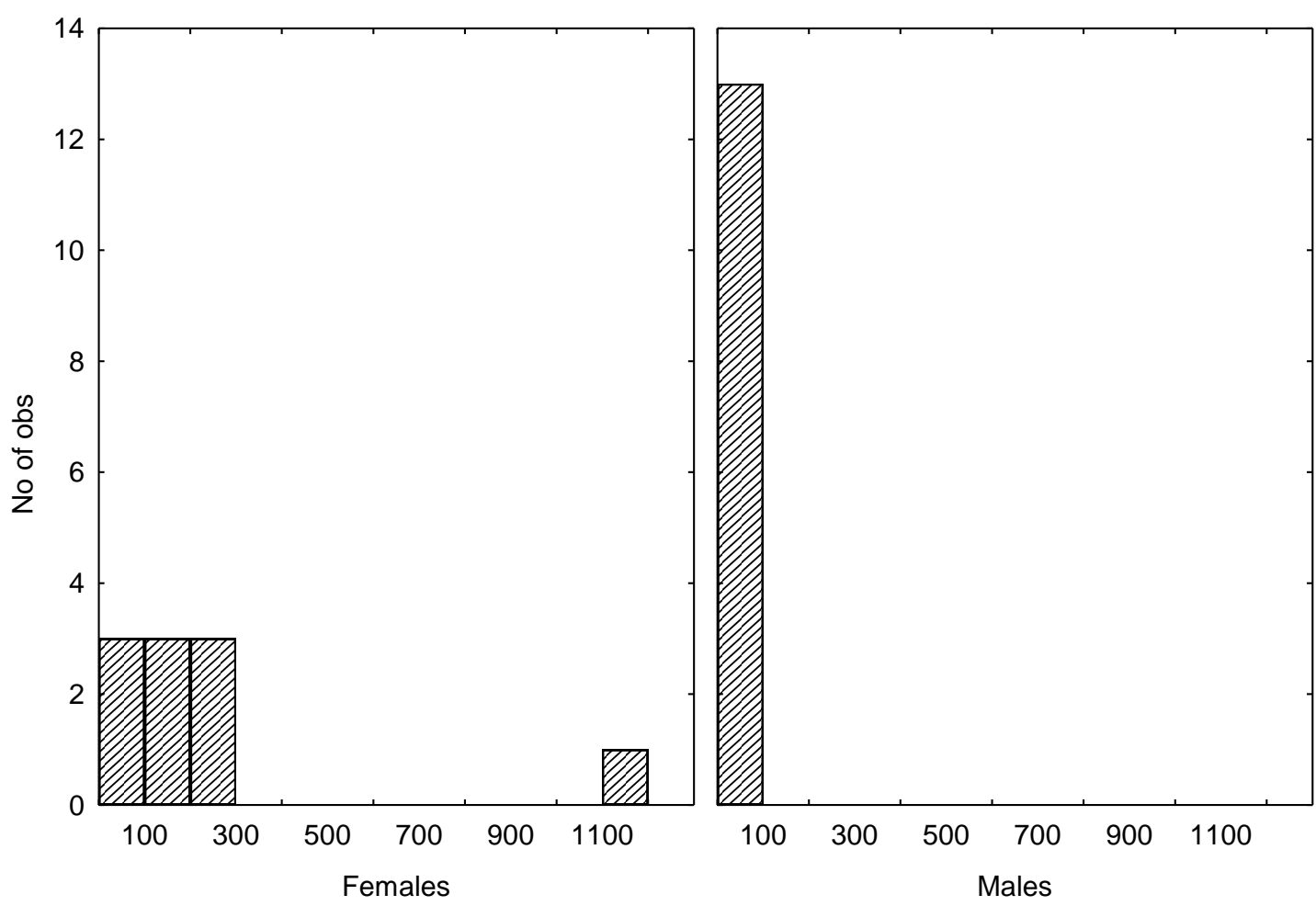

566

Natal dispersal distances $(\mathrm{Km})$

567

568

569

570

571

572 
